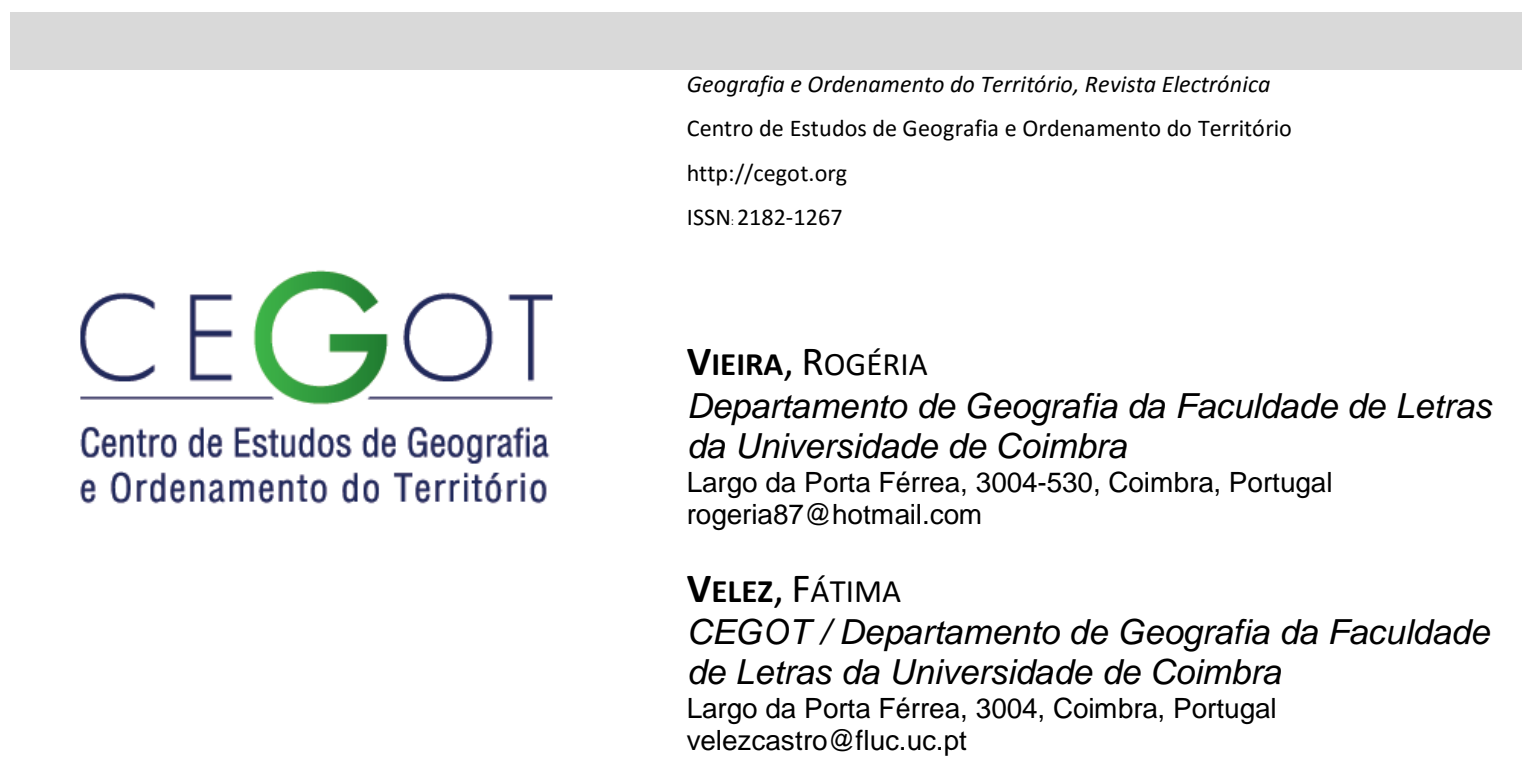

\title{
O contributo do cinema para a educação geográfica. Um recurso didático em Geografia das migrações
}

\author{
The contribution of cinema to geographic education. A didactic resource on \\ Geography of Migrations.
}

Referência: Vieira, Rogéria; Velez, Fátima (2016). O contributo do cinema para a educação geográfica. Um recurso didático em Geografia das migrações. Revista de Geografia e Ordenamento do Território (GOT), n.ㅇ 9 (junho). Centro de Estudos de Geografia e Ordenamento do Território, p. 307-322, dx.doi.org/10.17127/got/2016.9.014

\section{RESUMO}

Ao pensar em propostas inovadoras na aprendizagem em geografia, o cinema surge como instrumento metodológico de relevância, por contribuir para a construção do conhecimento sobre a realidade territorial. O filme "O Visitante", Thomas MacCarthy (2007) é um bom instrumento de análise para o estudo em geografia das migrações, por contribuir na construção do conhecimento, oferecendo a compreensão das razões e as consequências das migrações, considerando os grandes ciclos migratórios internacionais. Apresentaremos assim uma breve reflexão sobre a aplicação dos conteúdos programáticos, em estreita relação com a arte cinematográfica quotidiana, do ponto de vista didático.

Palavras-chave: Ciclos Migratórios. Cinema. Educação Geográfica. Geografia das Migrações.

\section{ABSTRACT}

Thinking about innovative learning proposals in geography, cinema emerges as relevant methodological tool, by providing a contribute to the construction of the territorial reality. The film "The Visitor", Thomas Mccarthy (2007) is a good tool for analysis for the study of geography of migration, by the contribute to the construction of knowledge, offering an 
understanding of the reasons and consequences of migration, considering the major migratory cycles. So we present a brief reflection on the implementation of the syllabus, in close connection with everyday cinematic art, from the didactic point of view.

Keywords: Migratory Cycles. Cinema. Geographical Education. Geography of migration.

\section{Educação Geográfica e o Cinema}

É de grande valia na Educação Geográfica, a capacidade de aplicação dos saberes geográficos com base numa metodologia motivadora, sendo para isso fundamental a aposta em ações inovadoras e reestruturantes dos conteúdos. Tal perpassa pela superação das aprendizagens repetitivas e arbitrárias, sendo desejável a adoção de práticas de ensino direcionadas para o desenvolvimento da capacidade e aptidões de análise, interpretação e aplicação prática, assim como a capacidade compreensão e reflexão sobre fenómenos ocorridos a diferentes escalas (CASTELLAR, 2005: 220, 221).

O professor tem por isso um papel importante no processo de construção do conhecimento, pois assume o papel de mediador e de criador de condições, nomeadamente ao nível das estratégias e dos instrumentos, para a ocorrência de aprendizagens significativas, sendo por isso a questão didático-metodológica primordial para o sucesso do processo de ensinoaprendizagem. Esta é "entendida como um processo de construção da espacialidade que corresponde a orientar-se, deslocar-se no espaço". Ao ensinar é preciso "estimular, motivar, dar significado ao conhecimento para que o aluno possa aprender a pensar sobre o mundo em que vive", desenvolvendo assim o pensamento crítico sobre a realidade (CASTELLAR, 2011: 11, 13).

Tendo como base esta linha de raciocínio, pensamos que o Cinema se constitui como um instrumento metodológico de excelência no ensino da Geografia. Não substitui de todo a observação direta, muito menos o trabalho de campo, contudo apresenta uma perspetiva interessante sobre a relação entre dados recolhidos na realidade, em estreita relação com a visão do realizador. Neste âmbito, os filmes podem ser entendidos como fragmentos de uma problemática associada ao espaço objetivo e subjetivo, numa ambivalência também 
constituída pelo olhar do espectador, neste caso do professor, o qual aproveita tal recurso com propósitos didáticos.

O uso de recursos fílmicos como instrumentos de trabalho quebra a rotina, destitui o contexto de ensino-aprendizagem de uma abordagem repetitiva, gerando no aluno novas competências ao nível da observação geográfica. Olhar a paisagem, ainda que imaginadaficcionada, desperta a atenção da turma pela apresentação do enredo, gera a necessidade de querer saber mais, de relacionar a ação com a justificativa espacial do que se passa, associado à perspetiva dos lugares e das paisagens onde atuam as personagens. E se a Educação Geográfica contribui para a análise, interpretação do território, tanto na dimensão social, como na cultural e económica, o Cinema assegura-se como dando a possibilidade de pensar mais além do que o próprio cenário apresentado, ou seja, extrapolar para os conteúdos didáticos abordados pelo professor, tanto numa perspetiva hipotético-real de "filme-programa" e "programa-filme".

O contato com filmes é relativamente facilitado devido aos meios de comunicação presentes no quotidiano, a exemplo da televisão, internet, cinema, etc. Nisso, é preciso instigar uma leitura fílmica de forma a considerar os estudos sobre as temáticas oferecidas nos filmes, e a escola ganha papel fundamental nesse contexto por ela ter a capacidade de desenvolver a leitura e interpretação das linguagens cinematográficas, essa que contribui para a formação pessoal e social das pessoas (PEREIRA, 2012: 2).

A linguagem cinematográfica compõe um conjunto de técnicas que fazem com que o filme transmita mensagens reais, contribuindo assim, para o debate sobre conceitos presentes no dia-a-dia. Nisso "the geographer's interest is focused on how cinema contributes to conveying the 'feeling of a place' and identity", sendo o sentimento de pertencimento foco e importante no estudo das migrações (PALMA, 2009: 48).

Em Portugal, a disciplina de Geografia constitui obrigatória para alunos do Ensino Básico e opcional no Ensino Secundário, nas áreas de humanidades e de ciências socioeconómicas. 0 estudo de caso que se propõem visa apresentar uma possibilidade de trabalho no âmbito do tema das migrações, abordada na disciplina, com o objetivo de chamar a atenção para aspetos concretos dos projetos migratórios, com base na apresentação do filme "O Visitante", de Thomas McCarthy (2007). Embora seja alvo de discussão, defendemos que o 
conhecimento da realidade, fator importante na aprendizagem em Geografia (CLAUDINO, 2014: 4), pode ser apreendido através da ficção, uma vez que de certo modo as narrativas se constroem com base em factos reais. Os documentos fílmicos são assim entendidos como hipóteses de realidade, baseadas na construção e simulação de pessoas, paisagens e histórias.

No âmbito da Educação Geográfica, GONZÁLEZ (2011: 30) cita estudos de Horacio Capel e reflecte sobre o que é estudado em Geografia no sistema escolar e seu papel na formação básica dos indivíduos. Estes autores defendem que o estudo desta disciplina deveria ter mais importância no sistema escolar por três razões principais: "1) porque ya existe y es una ciencia con una larga y rica tradición intelectual; 2) porque es una disciplina con un gran valor educativo y formativo; y 3) porque hay problemas que la geografía, es decir los profesionales formados en el campo de la geografía, pueden ayudar a estudiar y resolver". Entendemos por isso que a Geografia é um campo rico por englobar conhecimentos impar na formação do saber, assim como por englobar na sua metodologia de trabalho um conjunto de técnicas e de instrumentos que vão além da ciência, também a outros campos como a arte.

GONZÁLEZ (Ob.Cit: 31) defende ainda que o conhecimento geográfico está integrado em duas áreas de desenvolvimento curricular; na definição da configuração geográfica e ao contexto social; nas ciências naturais. A própria ciência em si pode participar ativamente na análise das características e fatores que afetam a aprendizagem do aluno, pois são esses "sus deseos, expectativas sociales, valores culturales dominantes, relaciones de sus viviendas con el sistema urbano dominante o las relaciones sociales y familiares que determinan las emociones, afectos y razonamientos del alumnado"

Para que a Geografia possa contribuir na formação do indivíduo, é possível considerar alguns aspetos estruturais interdependentes que levem a ser mais inovador, mais justo e equitativo: um processo contínuo flexível para se adaptar aos contextos sócio espaciais na reflexão sobre a sociedade e seus parâmetros (se inserindo corretamente na mesma), onde cada grupo social vai questionar os seus valores, criando seus próprios critérios no mundo em que vivemos; assimilando a sua própria cultura por meio dos recursos cognitivos, buscando a melhoria na sociedade; sendo um ser humano melhor (BERMÚDEZ, 2005: 2). 
Sem dúvida que a Educação Geográfica contribui para atuação dos indivíduos no meio social em que estão inseridos, desde a escala local à global.

As competências geográficas são assim "entendidas como las capacidades de una persona para desempeñarse acertadamente en relación con el espacio", sendo essas proporcionais aos desafios apresentados no século XXI (BERMÚDEZ, Ob.Cit: 3). Sobre as competências geográficas que a Educação Geográfica deve fornecer, este autor aponta que estas estão na dimensão pessoal (incentivando a participação ativa nas decisões a serem tomadas, em especial sobre os recursos naturais e ecossistemas frágeis); envolvimento, capacidade e vontade de trabalhar com diversas pessoas de diferentes identidades culturais, em múltiplos locais; vivenciar e se relacionar com o(s) lugar(es).

Também REINFRIED e HERTIG (2011: 2) defendem que "Geographical education is one of the educational areas that teach learners the thinking skills required to understand and to act sustainably in the world. Without geography, young people are unprepared for an increasingly global future". A quotidianidade está relacionada com a compreensão do conhecimento geográfico, a sua dimensão epistemológica, estando presente na aprendizagem e nos valores educativos de um sistema escolar. É um saber fundamental para os alunos tomarem decisões como cidadãos esclarecidos, estimulando a actuação responsável e activa na sociedade. Esta construção dos saberes e do pensamento crítico é apoiada em parte pela investigação científica e pelas tecnologias da informação e comunicação, onde está incluída a dimensão cinematográfica. É por isso importante que os alunos adquiram conhecimentos e domínio dos conteúdos, através do desenvolvimento de metodologias de ensino e aprendizagem que proporcionem interação entre teoria e prática; a relação com outros campos do saber, como a pedagogia e psicologia ou a arte, num campo iminentemente interdisciplinar de conhecimento.

Inserido na metodologia de ensino-aprendizagem em Geografia, o cinema apresenta-se "na própria tradição geográfica, praticamente desde a génese do médium nos finais do século XIX", onde a criação de histórias faz do cinema palco de visão limitado pelo ecrã (AZEVEDO, 2007: 413, 414). Porém VELEZ DE CASTRO (2015: 232) defende que as obras de ficção em cinema se constituem como "importantes fontes de informação para o investigador, uma vez que podem fornecer pistas sobre a dinâmica de processos e de factos geográficos e 
sociais, que nem sempre são evidentes em contexto de análise bibliográfica, estatística ou até mesmo no trabalho de campo". Também para o professor, como instrumento de trabalho na lógica de "visualização-análise-debate" e contexto de sala de aula.

FERRAZ, LINHARES, CORREIA, LIMA e VIEIRA (2010: 05) defendem que por meio da análise fílmica é possível trazer à tona "problemáticas que se encontram presentes na vida de todos nós, temas contraditórios, como por exemplos, a relação construída entre indivíduos e sociedade, e é justamente sob esse amparo que são restituídas as contradições e dilemas trazidas pelas Representações Sociais".

Para que a interpretação cinematográfica aconteça é necessário que o professor tenha a preocupação de fazer uso de recursos que estejam de acordo com o filme a ser exibido. É preciso que os alunos consigam "interpretar, descodificar e compreender a informação de forma adequada e consentânea com os objetivos curriculares" (PEREIRA, 2012: 10).

O uso de materiais de apoio é importante para a compreensão do filme. Nisso, o guião é um dos instrumentos que o professor pode elaborar e utilizar por esse possibilitar assinalar as principais questões apresentados no filme. Com as análises apresentadas no guião é possível realizar debates que contribui para esclarecer sobre a temática abordada, pois no guião cada aluno apresenta sua interpretação do filme.

O cinema enquanto campo de análise geográfica tem o papel da compreensão da cultura, no entendimento e organização do espaço, tendo como um movimento que surgiu nas últimas décadas com trabalhos de autores como Peter Jackson, Dorren Massey e Denis Cosgrove, citados por AZEVEDO (2007: 422, 423), com o estudo analítico da produção e reprodução de significados de lugar por meio de diversos produtos culturais, na tentativa de compreender os significados das variadas formas culturais, "o cinema nas suas formas mais variadas ajudaria a compreender o papel da memória e da imaginação geográfica na criação das imagens dos lugares e na construção das paisagens culturais". Assim, e segundo a autora, a Geografia e o Cinema vêm apresentar uma relação interessante no campo da aprendizagem, pois "a Geografia do Cinema proporciona uma perspetiva crítica sobre as políticas culturais subjacentes à construção de um filme e à sua estruturação enquanto janela sobre a realidade geográfica". É pensando na realidade vivida e construída pela sociedade que a utilização de filmes na aprendizagem geográfica vem ganhando espaço, e é 
nesse contexto que foi pensado no estudo sobre a Geografia das Migrações por meio da análise fílmica apresentada neste trabalho.

\section{2. "O Visitante" (Thomas MacCarthy, 2007) como instrumento de trabalho em Geografia das Migrações}

NUNES, ALMEIDA e NOLASCO (2014: 13), definem as metas curriculares de Geografia do 3으 ciclo do ensino básico (7으, 8o e 9o ano), nas quais nos baseámos para fundamentar a pertinência da escolha do filme em causa, assim como para proceder à sua visualização e análise. Destaque-se o tema da "mobilidade da população", lecionado no 8 o ano de escolaridade e que contempla os seguintes objetivos:

1. Compreender as causas e as consequências das migrações - Distinguir migração de emigração e de imigração; caraterizar diferentes tipos de migração - permanente, temporária e sazonal; externa e interna; intracontinental e intercontinental; clandestina e legal; êxodo rural. Também explicar as principais causas das migrações; explicar as principais consequências das migrações nas áreas de partida e nas áreas de chegada.

2. Compreender os grandes ciclos migratórios internacionais - Caracterizar os grandes ciclos migratórios internacionais, através da interpretação de mapas com os fluxos migratórios; localizar as principais regiões/países de origem da população migrante e principais regiões/países de destino da população migrante; caraterizar a população migrante; referir os fatores atrativos/repulsivos que influenciam as migrações; discutir a importância dos movimentos migratórios na redistribuição da população europeia e mundial.

3. Compreender, no tempo e no espaço, as migrações em Portugal - caraterizar a evolução temporal da emigração em Portugal; localizar os principais destinos da emigração portuguesa; caraterizar a evolução da imigração em Portugal, referindo as principais origens dos imigrantes; caraterizar a situação atual de Portugal no contexto das migrações internacionais. 
São objetivos considerados adequados e pertinentes para o nível de ensino em causa, uma vez que permitem a análise de fenómenos migratórios numa perspetiva cronotópica, em especial a várias escalas territoriais. A utilização do filme justifica-se justamente pela possibilidade de contacto com uma realidade extranacional, com dinâmicas políticas, sociais e culturais distintas.

\subsection{A Sinopse do filme e a sua relação com o programa de Geografia do Ensino Básico} (8ㅇ ano)

Tendo em conta o facto da análise fílmica contribuir para a construção do conhecimento na aprendizagem em geografia, achou-se pertinente a apresentação de um caso prático através do filme "O Visitante", de Thomas McCarthy (2007). Pela análise, é possível entender como um filme apresenta ligações directas entre a ficção e os conteúdos didácticos da disciplina de Geografia do Ensino Básico (8o ano) no tema "mobilidade da população", em especial nos dois primeiros pontos: 1. Compreender as causas e as consequências das migrações; 2. Compreender os grandes ciclos migratórios internacionais.

A história passa-se nos Estados Unidos da América e trata a questão da dificuldade de regularização por parte dos estrangeiros indocumentados, mesmo daqueles que estão em situação de risco de insegurança no país de origem. A apresentação deste filme em contexto de sala de aula ganha interesse não só para a disciplina, como para a formação do aluno em termos de educação geográfica e cívica, pois a narrativa em causa, além de revelar o quotidiano desse grupo, humaniza-o pela da apresentação de histórias de vida, de percursos geográficos e sociais das migrações contemporâneas. Além disso interessa a posterior posição tomada pela comunidade autóctone, neste caso representada por uma personagem peculiar - Walter - um Professor Universitário de Economia, viúvo, que vive uma vida solitária.

Este, apesar das visíveis dificuldades aprende piano, numa espécie de homenagem à memória da sua falecida esposa que foi professora desse instrumento. O seu quotidiano é monótono e repetitivo. Ao ser designado para participar num congresso em Nova lorque, resolve ficar no apartamento que possui na cidade, onde o aguarda uma situação insólita: 
assim que entra em casa é surpreendido por dois jovens - um sírio e uma senegalesa - que lá residem há algum tempo, sem que disso tivesse conhecimento. Esclarecido o malentendido, percebe-se que o casal havia sido vítima de um golpe e por isso eles resolvem sair imediatamente do apartamento. Sem terem para onde ir, Walter convida-os a passarem a noite com ele até que encontrarem um lugar para se hospedarem. É o começo de uma relação de amizade entre estas três personagens.

O jovem - Tarek - é músico percussionista e Walter começa-se a interessar pelo tambor que o seu inusitado hóspede toca frequentemente nas noites da cidade e por insistência do rapaz ele começa a praticar. Um dia, a retornarem de um ensaio e ao entrarem no metro, o rapaz fica preso na roleta, o que leva os polícias presentes a pensar que se trata de uma situação de viagem ilícita. Porém, quando fazem a identificação de Tarek, tomam conhecimento de que se trata de um imigrante ilegal no país. Levado para o centro de imigração, fica detido e o Walter tenta de tudo para libertá-lo. Como sua namorada - Zainab - não pode ir até o centro de imigração por também estar ilegalmente no país, Walter tornase interlocutor entre o casal. Tarek deixa inclusive de contactar com a mãe - Moina - que acaba por ir à procura do filho.

Mas Walter tem que voltar para as aulas da universidade e à rotina. Consigo leva o instrumento e continua a praticá-lo, enquanto Moina fica a morar no seu apartamento em Nova lorque, mas por pouco tempo, pois o jovem acaba por ser deportado e a mãe acompanha-o ao seu país de origem. Após se despedir no aeroporto, Walter vai ao metro tocar o instrumento de percussão no mesmo local que, provavelmente, Tarek gostaria de ter tocado um dia com o Walter.

\subsection{A dimensão política da migração e o estatuto do migrante}

O "Visitante" é uma síntese pertinente de alguns conteúdos explorados na meta referente ao ponto 1. Compreender as causas e as consequências das migrações, sobretudo no que diz respeito à explicação da dimensão política da migração, assim como do estatuto do migrante no território recetor (FONSECA, 2005, 72). 
Um dos aspetos basilares do filme consiste na possibilidade de "distinguir (...) imigração". Segundo a Organização Internacional para as Migrações (OIM, 2015: s/p), um (e/i)migrante é aquele que está fora do seu local (país) de residência, fazendo-o num outro local (país) há um ano ou mais. Não estando para já em causa a questão da legalidade do processo, as três personagens imigrantes no filme estão nos Estados Unidos da América há tempo suficiente para poderem ser considerados como tal. Aliás, no caso de Tarek e da sua mãe, verifica-se que ambos já residiram em mais que um local no país, o que pode ser um indício de ligação topofílica ao território, se considerarmos que é aí que pretendem fixar-se de forma legal.

Por outro lado, e na senda deste tema, este documento fílmico é um bom instrumento para o objetivo do programa de Geografia que pretende "caracterizar diferentes tipos de migração: (...) clandestina". Tarek e Zainab vivem permanentemente em tensão, pois são imigrantes indocumentados. Apesar da indicação programática recair sobre o termo "clandestino" e "ilegal", sugerimos a utilização do termo "indocumentado". No primeiro caso parte-se do princípio que se trata de indivíduos que podem não ter qualquer tipo de documento identificativo (passaporte, visto, etc.), sendo que a entrada se faz com desconhecimento das autoridades. No segundo caso podem estar contempladas situações de indivíduos que entram no país de forma legal, contudo deixam de ter documentação válida. Por isso, as autoridades, do ponto de vista teórico, sabem que essa pessoa entrou no país. Como ambos os conceitos podem revelar uma conotação negativa do ponto de vista humanitário, se forem concebidos como termos que colocam em causa a própria existência humana, ao criar "cidadão de primeira" e "cidadãos de segunda", isto é, retirando um conjunto de direitos que, mesmo não lhes estando atribuídos, poderão vir a estar, sugere-se que os professores possam alertar para esta problemática e introduzir o conceito de "indocumentado".

Tarek e Zainab parecem estar sempre numa situação vigilante: primeiro desconfiam da boa vontade de Walter, sobretudo Zainab, no caso do convite para passarem mais dias na sua casa; depois nota-se um medo latente das autoridades policiais, do seu aparecimento. Moina sabe há algum tempo da indicação de partida por parte das autoridades do país, porém prefere ignorar "fugindo" dessa ordem, a enfrentar a situação e a decidir partir ou ficar e lutar pela permanência regularizada. Por isso, todos estes casos são de 
"indocumentados", uma vez que não possuem qualquer documento que os habilite a permanecer em território norte-americano.

Tal como defendemos anteriormente, a discussão com base no filme humaniza a questão das políticas imigratórias, pois o que se relata é a história dramática de uma mãe e um filho que fugiram à instabilidade social e política da Síria (ainda antes da situação de guerra atual). Esta reflexão de natureza fílmica ficcionada é muito importante, uma vez que extrapola a objetividade e cientificidade do programa, o qual explora a dimensão teórica e abstrata da dimensão migratória em contextos de insegurança.

Na sequência, é de todo desejável que se possa "explicar as principais causas das migrações". Até certo ponto, a motivação migratória de Tarek e da mãe é de cariz político e humanitário, por isso, e apesar de uma situação aparentemente contraditória, parece haver elementos para serem considerados "refugiados". O ACNUR (2015: s/p) refere que a Convenção para os Refugiados, de 1951, define esta figura como sendo "alguém que, temendo ser perseguido por motivos de raça, religião, nacionalidade, grupo social ou de opiniões políticas, se encontra fora do país da sua nacionalidade e que não pode ou, em virtude desse temor, não quer valer-se da proteção desse país." O pai de Tarek havia morrido e a decisão estava muito condicionada por esse fator e de instabilidade do próprio país.

Neste caso, é desejável o confronto: o que impede o pedido do estatuto? Embora o filme apresente apenas a fase final do projeto migratório, ou seja, o momento do confronto com a situação de indocumentado e o repatriamento, pode-se extrapolar sobre a dificuldade de obtenção do estatuto de refugiado, os elementos de prova, assim como a questão de quotas migratórias reservadas a esta população, como ponto sensível das políticas migratórias de países de acolhimento.

Há dois projetos sobrepostos: o de vida individual, que contempla a atividade de músico de Tarek, a sua relação afetiva com Zainab, a ligação com os amigos, com quem toca tambor, e com a cidade; o migratório, que se liga com o de vida, porém que está dependente de superiores estatais e de políticas nacionais e supranacionais, que o voltam a desterritorializar já em contexto de integração no território de acolhimento (Haesbaert, 2007: 25; Haesbaert e Limonad: 40, 2007; Fernandes, 2008: s/p). 


\subsection{Os sistemas e os modelos migratórios}

Tendo em conta a definição de "sistema migratório" na perspetiva de MALHEIROS (2005: 119-120) como a existência e manutenção, por mais de 5 anos, de stocks e fluxos de migrantes que ligam dois países, e interligando com os aspetos geográficos do filme, tornase pertinente a abordagem do ponto 2 das metas curriculares- Compreender os grandes ciclos migratórios internacionais.

Tarek é sírio, Zainab é senegalesa, Walter é norte-americano. A partir da relação estabelecida entre as personagens é possível materializar o objetivo "localizar as principais regiões/países de origem da população migrante e principais regiões/países de destino da população migrante", assim como "caracterizar os grandes ciclos migratórios internacionais, através da interpretação de mapas com os fluxos migratórios".

De acordo com BLANCO (2000: 47-48) trata-se de uma mobilidade associada ao período contemporâneo das migrações que se caracteriza, entre outros aspetos, pelo aumento do número de indivíduos em circulação, pelo incremento dos stocks de migrantes e pela complexificação da geografia das migrações. Se por um lado as migrações laborais - que se supõe ser o caso de Zainab - aumentam, quer ao nível da mão-de-obra pouco qualificada, quer ao nível dos quadros altamente qualificados, por outro há um crescimento sem precedentes da população deslocada por motivos de insegurança causada por motivos políticos e sociais - o caso de Tarek. Terá interesse explicar aos alunos que, por um lado, o filme revela uma personagem feminina que representa um movimento migratório "clássico", associado à motivação laboral e económica para emigrar; por outro, uma personagem masculina que representa um movimento migratório "emergente", no sentido em que cada vez mais urge repensar as políticas migratórias de base humanitária.

Walter representa o país de acolhimento e um dos destinos mais atrativos para concretização dos projetos migratórios. A sua evolução quanto à imagem sobre o "Outro" imigrante altera-se ao longo do filme, pelo que constatamos que ele se vai tornando uma "pessoa melhor", mais feliz, pelo contacto com os seus amigos estrangeiros. Esta é uma mensagem fílmica de grande importância para a Educação Geográfica e para a formação dos 
alunos enquanto cidadãos, pois ajuda a olhar o "Outro" com as suas diferenças, especificidades, a interpretar a quotidianidades, o que vai eliminando eventuais barreiras de nacionalidade. A partir do momento em que Walter partilha os dias com Tarek (conversando com ele, tocando tambor com os amigos, etc.) e com Zainab (quando toma conta da sua banca, na rua/local onde vende artesanato), vai esbatendo prováveis preconceitos geográfico-culturais sobre a origem médio-oriental ou africana, passando a encarar estes indivíduos como "pessoas" como ele próprio, na plena acepção da palavra. Esta posição é corroborada pelos esforços que Walter envidada para reverter a situação de expulsão do amigo, trabalhando inclusive com Moina, a mãe de Tarek.

Também é possível a prossecução de outro objetivo "referir os fatores atrativos/repulsivos que influenciam as migrações", tendo como base o quadro teórico em migrações. Pela dinâmica da história, optámos por destacar uma teoria que pode explicar a motivação da mobilidade - a teoria da atração-repulsão, de Ernest Ravenstein. "Segundo o autor, a decisão de se migrar de um determinado território para outro, é tomada com base num binómio geográfico em que se consideram as vantagens e desvantagens económicas, laborais, sociais, etc. de residir e trabalhar no local 1 versus o local 2. Partia-se então do princípio que na origem de uma migração, estariam sempre em destaque a influência de fatores repulsivos do local 1 (por exemplo, desemprego, baixos salários, fracas oportunidades de ascensão profissional ou académica, etc.). Em contraposição, no local 2 o migrante colocaria em evidência fatores atrativos (por exemplo, disponibilidade de emprego, salários elevados, oportunidades de formação profissional e académica, etc)" (VELEZ DE CASTRO, 2012: 205). Tanto Tarek como Zainab saem dos seus países não em busca de uma experiência migratória de âmbito académico ou profissional, mas antes porque percecionam fatores negativos - insegurança física e pobreza. Os Estados Unidos da América afiguram-se como o el-dorado, o território de possibilidades de estabilidade em termos físicos, emocionais e económicos, constituindo-se como atrativo.

Outra teoria também patente é a do mercado de trabalho segmentado, estruturada por Michel Piore, a qual preconiza que os imigrantes, de uma forma geral, não entram em concorrência com os nacionais, em termos laborais, uma vez que tendem a desempenhar funções num segmento "secundário", isto é, pior remuneradas, menos seguras e 
reconhecidas do ponto de vista social, por vezes preteridas pelos próprios autóctones (ARANGO, 2004: 24; ACIDI, 2008: 6).

Nas cenas onde Tarek toca tambor num restaurante, e nas cenas onde Zainab vende seu artesanato, pode-se extrapolar a questão salarial e sua diferença perante o restante da sociedade nativa. Por outro lado, Zainab parece estar numa zona de comércio da cidade bastante etnicizada, ou seja, onde a economia local se baseia na venda ambulante de artesanato por parte de imigrantes. Em ambos os casos, não parece haver situação de concorrência com os nacionais, sendo que ambas as personagens desempenham funções relativamente importantes - arte e estética - para a comunidade local. A essa dinâmica associa-se o conceito de "embeddednesse", que significa "forte grau de relação entre ação económica e estrutura social, que nesta perspetiva é sublimemente representado no filme (PEIXOTO, 2004: 9).

Esta última teoria é importante do ponto de vista da Educação Geográfica para a cidadania, uma vez que desconstrói o estereótipo de que os imigrantes tendem a usurpar postos de trabalho aos nacionais, o que normalmente não acontece. Também para mostrar aos alunos que as funções de ambos no mercado de trabalho e na sociedade são válidas e que contribuem para manter a estrutura de serviços e bens demandados pela população da cidade.

\section{Conclusões}

O cinema tem ganho destaque na promoção do conhecimento nas escolas por retratar temas importantes que estão presentes nos conteúdos didáticos, sendo possível por meio desse, estimular a construção do conhecimento. Na educação Geográfica, o cinema têm contribuído de forma bastante significativa, revelando um importante instrumento no ensino-aprendizagem em geografia.

O uso de métodos inovadores como a análise fílmica permite obter diferentes hipóteses de abordagem dos fenómenos geográficos, pelo que o filme questões reais e leva para a sala- 
de-aula discussões do dia-a-dia do educando, sendo uma motivação da aprendizagem. Este constitui em um rico instrumento de aprendizagem por ser dinâmico e apresentar uma diversidade de linguagens e símbolos que facilitam a interpretação, estimula a visão e audição, desenvolvimento a capacidade intelectual e criativa dos alunos (PEREIRA, 2012: 9). O estudo de caso prático do filme "O Visitante", de Thomas McCarthy (2007), revelou-se em um importante instrumento de análise no tema das migrações. A história de vida apresentada no filme em análise além estimular o debate sobre as questões das migrações, contribui para a humanização dos alunos pela história dos personagens que vivem numa situação dramática.

O estudo aqui apresentado expõe que por intermédio do cinema é possível enriquecer a aprendizagem geográfica, sendo a ligação ficção-realidade uma forma de despertar o interesse dos alunos pelo mundo e os territórios que os rodeiam.

\section{Referências}

ACIDI, Alto Comissariado para a Imigração e Diálogo Intercultural. "Imigração: os mitos e os factos". Biblioteca infoeuropa (Online), 2008, (consultado em 12 Outubro 2015), pp. 01-24. Disponível na World Wide Web: < http://www.infoeuropa.eurocid.pt/registo/000044407/>.

ACNUR. Agência da ONU para os Refugiados (Online). 2001-2015 (consultado 07 Julho 2015). Disponível na World Wide Web: <http://www.acnur.org/t3/portugues/>.

ARANGO, Joaquin. Theories of international migration. In JOLY, Danièle. International migration in new millenium. Reino Unido: Ashgate, 2004, p.15-35.

AZEVEDO, Ana Francisca de. Geografia e cinema: representações culturais de espaço lugar e paisagem na cinematografia portuguesa. Tese de Doutoramento em Geografia, ramo do Conhecimento de Geografia Humana, Universidade do Minho, Braga, 2007.

BERMÚDEZ, Oscar Buitrago. La educación geográfica para un mundo en constante cambio. Biblio 3W. Revista Bibliográfica de Geografía y Ciencias Sociales, Universidad de Barcelona, enero 2005, vol. X, no 561.

CASTELLAR, Sonia Maria Vanzella. A superação dos limites para uma educação geográfica significativa: um estudo sobre a e na cidade. Revista Geográfica de América Central, II Semestre 2011, no especial EGAL, p. 1-25.

CASTELLAR, Sonia Maria Vanzella. Educação geográfica: a psicogenética e o conhecimento escolar. Cadernos Cedes. Maio/agosto 2005, vol. 25, no 66, p. 209-225.

CLAUDINO, Sérgio. Escola, educação geográfica e cidadania territorial. In El control del espacio y los espacios de control: actas do XIII Colóquio Internacional de Geocrítica, 13, Barcelona, Mayo 2014, p. 1-9, Espanha.

FERNANDES, João Luís J. Insegurança ambiental e migrações. Contributo para uma sistematização de conceitos. Quinto Encuentro "Migraciones, causas y consecuencias, Eumed.Net, Universidade de Málaga, 2008, Espanha. 
FERRAZ, Ana Flávia de A.; LINHARES, Ana Luna de S.; CORREIRA, Anne Elizabeth dos S.; LIMA, Roberta Maria de O.; VIEIRA, Rogéria de Souza. Reflexões sobre as questões de gênero na paisagem árida. Cinema Caipira Ou do interior paulista, Grupo Kino-Olho (Online). Outubro 2010, no 20 (Consultado em 06 Julho 2015), pp. 04-06. Disponível na World Wide web: <http://www.readoz.com/publication?i=1030153>.

FONSECA, Maria Lucinda. Migrações e Território. Estudos para o Planeamento Regional e Urbano, CEG, no 64, Lisboa, 2005, p. 220.

GONZÁLEZ, Xosé Manuel Souto. Una educación geográfica para el siglo XXI: aprender competencias para ser ciudadano en el mundo global. Revista virtual - geografía, cultura y educación (Online), 2011, no 1 (Consultado em 05 Maio 2015), pp. 28-47. Disponível na World Wide Web: < http://www.anekumene.com/index.php/revista/issue/view/2>.

HAESBAERT, Rogério. Território e multiterritorialidade: um debate. GEOgraphia (Online), 2007, ano IX, vol. 9, no17 (consultado em 05 Maio 2015), pp.19-45. Disponível na World Wide Web: < http://www.uff.br/geographia/ojs/index.php/geographia/issue/view/19>.

HAESBAERT, Rogério; LIMONAD, Ester. O território em tempos de globalização". ETC-Espaço, Tempo e Crítica, Revista Electrónica de Ciências Sociais Aplicadas (Online), julho-setembro 2007, vol 2, №2(4), (consultado em 05 Maio 2015), pp.30-52. Disponível na World Wide Web: < http://www.uff.br/etc/>.

MALHEIROS, Jorge. Migrações. In: MEDEIROS, Carlos Alberto. Geografia de Portugal. Sociedade, Paisagens e Cidades. Rio de Mouro, Circulo de Leitores, 2005, p.87-125.

NUNES, Adélia; ALMEIDA, António Campar; NOLASCO, Cristina Castela. Metas Curriculares do 3o Ciclo do Ensino Básico (7ํ, 8o e 9o anos). Geografia. Lisboa: Ministério da Educação e Ciência, 2014.

OIM. Organização Internacional para as Migrações (Online). 2015 (consultado 02 Julho 2015). Disponível na World Wide Web: <http://www.iom.int/>.

PALMA, Maria Teresa di. Teaching Geography Using Films: A Proposal Journal of Geography. Journal of geography (Online), 2009, vol. 108 (consultado em 07 de Outubro 2015), pp. 47-56. Disponpivel na World Wide Web: <http://dx.doi.org/10.1080/00221340902967325>.

PEIXOTO, João. “As Teorias Explicativas as Migrações: Teorias Micro e Macro-Sociológicas”. SOCIUS Working Papers (Online), 2004, n. 11 (consultado em 07 de Outubro 2015), pp. 01-36. Diponível na World Wide Web: < https://www.repository.utl.pt/bitstream/10400.5/2037/1/wp200411.pdf>.

PEREIRA, Pedro Daniel Martins. Geografia e cinema: O cinema enquanto recurso educativo na aprendizagem de História e Geografia: Uma exploração com alunos do 8o ano de História e alunos do 11a ano de Geografia. Dissertação de Mestrado em Ensino de História e de Geografia no 3o Ciclo do Ensino Básico e no Ensino Secundário, Universidade do Minho, Braga, 2012.

REINFRIED, Sibylle and HERTIG, Philippe. Geographical Education: how human-environment-society processes work. Encyclopedia of Life Support Systems (EOLSS) (Online), 2011 (consultado 05 Maio 2015). Disponível na World Wide Web: <www.eolss.net/sample-chapters/c01/e6-06b-46.pdf>.

VELEZ DE CASTRO, Fátima. Ruralidades urbanas. Espaços (ir)reais na obra de Pedro Almodovar. In Intervalo entre Geografias e Cinemas (Online). AZEVEDO, Ana Francisca; CERAROLS, Rosa; OLIVEIRA JR, Wenceslao Machado. Braga: UMDGEO Departamento de Geografia da Universidade do Minho, 2015. (consultado 02 Julho 2015). pp. 229 - 250. Disponível em RepositoriUM da Universidade do Minho. ISBN 978-989-97394-9-9.

VELEZ DE CASTRO, Fátima. Imigração e territórios em mudança. Teorias e prática(s) do modelo de atracçãorepulsão numa região de baixas densidades. Cadernos de Geografia (Online), 2011-2012, nำ30/31 (consultado em 02 Julho 2015), pp. 203-213. Disponível na World Wide Web: < http://www.uc.pt/fluc/depgeo/Cadernos_Geografia/Numeros_publicados/CadGeo30_31>. 